\title{
Olympic Movement or Diplomatic Movement? The Role of Olympic Games on Development of International Relations
}

\author{
Mahdi Shariati Feizabadi ${ }^{1}$, Fernando Delgado ${ }^{1}$, Mohammad Khabiri ${ }^{2}$, Nasrollah Sajjadi $^{2}$ and Ebrahim Alidoust ${ }^{2}$ \\ 1. Department of Communication Studies and Theater Arts, University of Wisconsin River Falls, River Falls City, Wisconsin 54022, \\ USA
}

2. Department of Sport Management, University of Tehran, Tehran, Tehran 1438, Iran

\begin{abstract}
The Olympic Charter is categorized into three main sections: the IOC (International Olympic Committee), the IFs (International Federations) and NOCs (National Olympic Committees). Since the 1980s, the prominent functions of sport and in particular mega events such as the Olympic Games have been deeply analyzed by academic and political writers. Sporting mega events like the Olympic Games can produce lots of advantages: international branding and prestige, economic development, unity and cooperation, cultural exchanges and interactions, reduction in political isolation and sanctions, and so on. One of the most important legacies of Olympic Games for the host country/city is social cohesion, national pride and patriotism. For example, the success of Iran in the London 2012 Olympics resulted in heightened cultural identity and national prestige. Despite political and economic isolation resulting from international sanctions, Iranian athletes and coaches overcame obstacles to win four Olympic gold medals in "Mega Media Event" that is the summer Olympic Games. The present study demonstrates the interconnections between success in the Olympic Games and the development of nations. The data to support the analysis and arguments were gathered through public documents and interviews with sport diplomacy experts. At first, we investigated some international functions for sport, then we had 13 interviews with 11 Iranian and 2 foreign experts who had international positions in different sport organizations like IOC, Ifs, FIFA (Federation international the Football Association) and OCA (Olympic council of Asia). Finally, all information was organized into the following factors: enhancing international branding and prestige, international image, number of sport tourists as virtual industry in new millennium, national cohesion and identity, national patriotism, peacefulness, cultural exchanges among nations and reduce political boycotts and economic sanctions.
\end{abstract}

Key words: Olympic, International Relations, Iran.

\section{Introduction}

Public diplomacy is a new diplomatic studies area. Fisher describes public diplomacy as the result of three components: cultural exchanges, cultural diplomacy, and media casting. Because of the intersecting phenomenon of international sporting events-which traverses cultural exchanges, diplomacy and transnational organizations, and the prevalence and influence of the mass media on sport-international sport can play an important role

Corresponding author: Mahdi Shariati Feizabadi, Ph.D., research field: sport management. E-mail: mahdi.shariatifeizabadi@uwrf.edu. in the entire public-private continuum at any point [1]. Fused together, sport diplomacy create a hybrid concept, "sport diplomacy", which has a critical role in diplomatic history [2].

For centuries, sport has been a vital part of community and nation building and its relationship with the political sphere (especially diplomacy) has a long tradition of cooperation and synergy. Although sport diplomacy as a sub-branch of public diplomacy has attracted much attention in recent years, the relationship goes back to the 9th century $\mathrm{BC}$. The kings signed an "Olympic Truth" during the first festival of the ancient Olympic Games. They agreed to 
suspend all violent and hostile behaviors by the time of the event to provide enjoyment for audiences and athletes. The relationship between sport and diplomacy has been reinforced over time, and the "Olympic Truth" continues to serve as a reminder of the importance of sport diplomacy throughout the twentieth century (which saw unparalleled growth in global media and international sport) and increasingly so in the new millennium where ideas, politics, culture, and sport impact and influence international relations [2].

In fact, it may now be impractical to separate the concepts of sport diplomacy and public diplomacy, as sport becomes increasingly a vehicle for economic development, political agendas, and governments' diplomatic tactics. Diplomatic efforts are often facilitated by traditional diplomacy, the use of sporting events and even athletes (as celebrities and national icons), and the articulation of national goals that shape foreign policy and relations and are integrated with (even overlapping) transnational sporting and political organizations. Thus, sport can be deployed as a tool of and for diplomacy cutting across national, cultural, non-governmental, and media spheres. Fig.1 indicates the level of awareness toward and elements associated with sport diplomacy through the 2010 London Olympic Games:

Although traditional diplomacy has been designed to achieve diplomatic goals, Murray identifies seven reasons for articulating the sport diplomacy concept [3].

Changes in diplomacy space lead to tying sport and diplomacy together. Sport is an indirect tool to achieve foreign policy objectives. The image of a country's foreign policy can be shaped by the use, presence, or absence of sport and influences outside perception of a nation as closed, isolated, open, or popular.

Sport and its associated institutions are on the rise across cultural and national consciousness-imbricated with economic and social power, cultural influence, and even people's identities. As global media and sport, David Beckham has stated "No one is opposed to sport; sport has an international quality and it's kind of epidemic".

The public are tired of widespread violence in the new millennium. Consequently, diplomats and political leaders often use soft power such as cultural and sport exchanges to resolve their conflicts. In the postmodern age, sport and culture are powerful tools of foreign policy and transcend the more traditional boundaries of international relations.

Sport has a global audience and is a huge part of quotidian life. If the pictures and diplomatic messages transmitted through positive sport values have influence, then perceptions of nations can be improved

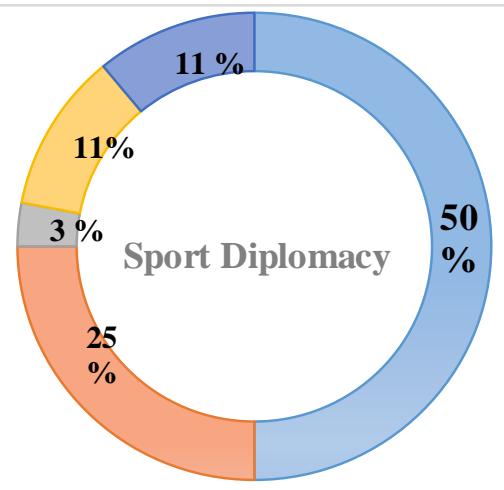

Fig. 1 Released papers about different parts of sport diplomacy. 
and the strategies of foreign policy changed. For instance, the Beijing 2008 Summer Olympic Games provided an opportunity for China to introduce itself as an economy, culture, and people to an international community.

Convergence and increasing proximity of sport and diplomacy to each other. Jim Cain, former U.S. ambassador to Denmark, observes "Sports can be a powerful tool for achieving the relationships among the governments". Sport carries a positive message in the context of common values such as mutual respect, tolerance, compassion, discipline. These values, in turn, can positively influence the presence of racism, the experience of xenophobia, and bridge cultural and political divisions. In this way, sport can support and extend effective foreign policy toward oriented toward positive international relations. After Black September (September 11, 2011), USA applied sport as a way to attract Muslim youth in Africa and the Middle East. Sport provided a vehicle for the US to connect with people across broad national, ethnic, and religious difference. This tactic reinforced, across even disparate tribal and ethnic groups, commonalities and orientations toward human rights and mutual respect. Thus, while respecting differences in language, local traditions, customs, etc., the use of sport reinforces a more universal experience and a space for intercultural contact and awareness.

Globalization is another reason and resource to interact and integrate diplomacy and sport together. As Markovits and Rensmann note "political campaigning, governing, and symbolic politics often entail references to sport", perhaps this is so because athletes and politicians travel in a space of public awareness focused on each group's roles and responsibilities within cultural and political spheres. Consequently, sport and diplomacy are drawn toward each other like magnets - each having their force but often attracted to one another via their import and influence on citizens, voters, and consumers. Perhaps the affinity is primordial—both the athlete and the diplomat compete is races where winning and losing is eminently observable and measurable and the drama draws an audience irrespective of the competition's locale — racing oval or meeting room table [4].

Lastly, sport diplomacy provides a soft path to reveal a significant change in a nation's foreign policy agenda. The best example of this is perhaps the Ping Pong diplomacy between China and the US in 1971 or, more recently, the 2011 if cricket diplomacy between India and Pakistan, where Gilani (Pakistan Prime Minister) invited his Hindi counterpart Singh to attend and watch the semifinal match of cricket world cup in south Asian countries [3].

Over the past three decades, hosting sport mega events (like the summer or winter Olympics or the FIFA World Cup) has emerged as a prominent political phenomenon and it is one of the emerging economic resources for governments [5]. The mega events are important in the international arena-they provide a venue for global public attention and create a powerful platform for a nation desiring to articulate a particular image of itself (as developed, cosmopolitan, friendly, safe, etc.). Mega events have many determinant features like: the increased number of tourists, trade, reputation of host city/country in the world, and the development of infrastructure in the host country/city [6]. Numerous studies in relation to each of terms "Mega Event", "Major Event", "Hallmark Event", "Wide Scale Event" and "Special Event" were presented. By considering all these definitions, the term "Mega" is different due to effect of event on host city/country [2]. Politicians run the political processes at community and influence large non-governmental organizations such as the IOC or FIFA [7].

The Olympic Games, as an example of a huge cultural event, reminds us the potential for "Sport Diplomacy". The IOC prepared an appropriate space for gathering disparate nations in a calm place and remove conflicts and governmental enmity. This happens by athletic heroism, the competitive spirit, 
and the values of the Olympic charter even for a short period of time [8]. The concept of "Olympic Diplomacy" has two main vectors: the first one is the intrinsic value of sport, even if experience in the transient manner of a match or competition, for diplomatic dialogue and safe space for competition between nations. The other is that sport can highlight the space of conflict and facilitate friendship or very visibly offer an opportunity for protest. The reaction of many nations to the Soviet invasion to Afghanistan in December 1979 and subsequent boycott is but one example where a mega event, and the attention is draws globally, serves as a space for nations to articulate the state of their diplomatic relations [3].

\subsection{Media Roles, International Relations and Sport}

The increase presence and value television are interconnected with the Olympic Games, each influencing each other in the mutual goal of generating larger audiences and more revenue. Technological advances in the mass media have enabled the Olympic Games to become more accessible to audiences throughout the globe. While the IOC sees the media broadcasting rights as the main source of its revenue, sport is the most important source programming, from a commercial perspective, for the media [9]. The Rome 1960 Summer Olympic Games was the first the time television broadcast Olympic events live casting. In the fifty years since then, media conglomerates have competed for the broadcasting rights, with the costs spiraling upward from the slightly more than $\$ 1.2$ million paid in 1960 to over one billion dollars spent on recent broadcasting rights. The introduction of broadcasting provided a brilliant opportunity for home audiences to watch games like the stadium spectators and to expand the fan experience-redefining the Olympics as global mega event. People in 18 countries, including Japan, Canada and USA watched those 1960 Olympic Games. Shariati Feizabadi explained the number of territories covered by Olympic Games in Table 1 [10].

Since the 1984 Los Angeles, broadcasting rights have exploded and their relevance and import has reinforced and grown the Olympic Games-there is now a symbiosis between broadcasters and the Olympics. This in turn has fueled greater opportunities for sponsorship and associated revenue, driven ticket sales (thought this uneven), created larger opportunities for merchandising, and encouraged competition for hosting the games because of the perception of prestige and direct or indirect benefits of having millions of people come to the host city and billions able to see the host city through their televisions and computer screens. Indeed the commercialization of the Olympics has grown dramatically since the 1984 summer games and the IOC has seen the opportunity to increase sponsorships and the expansion of broadcast rights sales. One of the beneficial outcomes for political, community, and economic boosters within a host city is the potential for investment and development of infrastructure to secure hosting rights as the scale of the event has grown.

Table 1 Number of territories covered by Olympic broadcasting.

\begin{tabular}{|c|c|c|c|c|c|}
\hline Year & Host & No. of Territories & Year & Host & No. of Territories \\
\hline 1980 & Moscow & 11 & 1936 & Berlin & 1 \\
\hline 1984 & Los Angeles & 156 & 1948 & London & 1 \\
\hline 1988 & Seoul & 160 & 1952 & Helsinki & 2 \\
\hline 1992 & Barcelona & 193 & 1956 & Melbourne & 1 \\
\hline 1996 & Atlanta & 214 & 1960 & Rome & 21 \\
\hline 2000 & Sydney & 220 & 1964 & Tokyo & 40 \\
\hline 2004 & Athena & 220 & 1968 & Mexico city & $\mathrm{Na}$ \\
\hline 2008 & Beijing & 220 & 1972 & Munich & 98 \\
\hline 2012 & London & 220 & 1976 & Montreal & 124 \\
\hline
\end{tabular}


Thus local leaders can often secure private and public investment in projects, while other local sectors related to tourism and hospitality profit from sponsors, tourists, and ticket sales [12].

During this period of expansion of the broadcasting and commercialization, there has been a growth in the territories and region where the games are covered. The Sydney 2000 Olympic Games were the first to broadcast to 220 different countries and regions. On the other hand, Beijing 2008 Summer Olympic Games was the first fully digital games in the world's biggest sport event history that $63 \%$ of the global population (4.3 out of 6.7 billion people) had access to watch the games live. This tournament was the biggest "Media Event" in the world [10].

\subsection{Sport Functions in International Relations}

Across the historical place of sport, today sport has become the focal point of community.

Bainvel summarized the functions of sport in the following [13]:

A tool for promotion of power and domination

A phenomenon to strengthen political ideology

A tool to destroy peacefulness

A way for provoking enmities

A tool to estimate and out graded nations

A tool for damaging the neutralized relations

A tool for revenge

Kind of easy business

A way to hide doping

A tool for tampering

A tool for racism

A tool for physical and verbal violence

A way to increase patriotism

A tool for integrating the minorities and tribes

Contributing tool for peace

A tool for encouraging the nationalism

A way to improve international relations

A way for strengthening peacefulness

A tool for nation's friendship

A way for increasing tolerance and kindness
A tool for reducing conflicts

A way for creating chivalry spirit

A tool for analyzing an especial

A way for explaining the opposes situation

\subsection{International Branding, Prestige and Image}

Sport is a way to influence the image of a nation, and producing what is called "Soft Power" or "Social Capital". The foundational elements of public diplomacy are listening or engaging a foreign public by collecting and analyzing its opinions and feeding that to the formation of policy; Advocacy through direct representation of information and policy; cultural diplomacy through the participation in and facilitated export of culture exchange; diplomacy as the mutual exchanges of personnel with foreign partner; international broadcasting engaging foreign audiences through direct delivery of news. All these elements, which Joseph Nye famously labeled as "Soft Power," work together with policies and cultural values of society [23].This is especially true for newly founded countries that are faced with financial constraints and where sport can be a precious alternative for other symbolic or raw materials [2]. "National Branding" is a new form of public diplomacy among the countries where sport is the easiest way to achieve that goal [14]. Sport as national brand can facilitate governments in their pursuit of achieving their commercial or political goals [2]. For instance, "Sport Nation" was one of the Australian images before, during and after Sydney 2000 Summer Olympic Games. According to Australian tourist Commission report, the successful outcome of Games leaded to improving Australia's image as much as 10 years, and it shows the correct management of image by organizers [14].

\subsection{Sport Tourism: "Virtual Industry" in New Millennium}

Besides cultural and archaeological tourism, many tourism attraction types have come into existence and 
addressed broader segments of tourists across the world, including recreational tourism, beaches tourism, religious tourism, therapeutic tourism, eco-tourism, sports tourism, golf tourism, safari tourism, desert tourism, yacht tourism, and maritime tourism in addition to festivals tourism, and cultural events and finally conferences and exhibitions tourism. Sport tourism can be seen as like the fine arts and theater: players are akin to artists, spectators become the audience, and stadiums are the theaters [15]. Small countries can benefit from hosting sport events proportionally. The Cook Islands, with a population of 13,000, are near New Zealand and hosted 100 thousand tourisms annually. Over the past decade, the islands have several projects for the construction of sport facilities and infrastructures such as 3000-seat national stadium. The islands hosted "Pacific Mini Games" where 22 islands competed in 15 sport disciplines. The other sport event was "World Youth Netball" championship where 20 countries participated in those games. These islands have hosted the "Bowl" tournament in 2009. It was one of the seventh major events in rugby field that resulted in 34500 tourists to islands [1].

\subsection{Sport, National Identity, Cohesion and Patriotism}

Sport is frequently a vehicle for the expression of nationalist sentiment to the extent that politicians are all too willing to harness it for such disparate, even unethical purposes as nation building, promoting the nation or giving cultural power to separatist movements [24]. The integrative role of sport for a nation is similar to its structured functional role that can be been found in classical and social science studies. Sport can allow for local, regional, or even national differences and still provide a space to deal with diversity, racism, tribal and regional conflicts within a country. Indeed, this safe zone for disparate peoples to come together is a central reason that causes people to participate in sport events and, on a larger scale, undergirds the value of the Olympic movement [16]. For example, a country tried to employ players from other nationalities to use sport as a national pride tool. As Qatar did by employing Bulgaria's weightlifters [8]. As former IOC president Avery Brundage ${ }^{1}$ has stated "Sport as well as music and fine arts can be paled the political and ethnical boundaries; we can stay together through sport, and politic or business never be realized this cohesion, lonely" [8].

\subsection{Sport, Political Boycotts and Economic Sanctions}

Isolation and sanctions can be placed in the context of development. Politicians and policy makers talked about "political development" phenomenon at first, then the economists, sociologists and political scientists focused on the importance role of policy. The collocation "political development" has a precise definition. This refers to several studies from the perspective of inter disciplinary studies of "growth", "modernization" and "development" in the Third World [17].

Sport as an arena for diplomatic strife arena can occur, and isolation and global development are the double-edged sword of sport. The cold war opponents boycotted each other's games in 1980 and 1984. USA plus 64 other countries boycotted Moscow 1980 Summer Olympic Games because of Soviet invasion to Afghanistan. This led to only 80 countries participating in those games. Since 1956, this was the lowest number of nations in the Olympic Games. On the other hand, Soviet Union and 14 other countries from East Bloc (except Romania) refused to participate in 1984 Los Angeles with the excuse of unsafety [18].

\subsection{Sport and Its Peacefulness Role}

Many authors have suggested that sport has potential to reduce tension among competitors in international arena, and it can integrate diversity and inequality in a country. Regardless of language, race,

\footnotetext{
${ }^{1}$ Former President of IOC during 1952-72
} 
ideology or culture, sport is capable to gather all people for creating and exciting humanitarian scene. For instance, Olympic rings symbolized the five continents and its white flag represent purity [19].

Sport cannot impose or maintain peace, but it can inspire it. Sport has a vital role to play as it continues to demonstrate that it can facilitate dialogue between different communities and be a catalyst for mutual understanding in global society [24].

\subsection{Sport Fields: An Arena for Cultural Exchanges}

Many experts talk about the common aspects of cultural relations and sport diplomacy, however, we can clarify this similarity by exploring some indicators. For example, cultural relations between nations and their peoples can be facilitated by political structuring of offices and ministries. A nation could create a special organization with the task of implementing strategy that could include establishing cultural centers, friendship associations, scientific and academic cooperation, cooperation between Radio and $\mathrm{TV}$, sports, tourism and the other kinds of cultural activities that can be helpful both to economic development and easing international tensions by encouraging contact and understanding [20]. Sport can therefore be a part of a government's public diplomacy strategy. Although sport is not the only form of diplomacy, it is an important part of cultural diplomacy (along with food, education, science, etc.) [8]. As compared to the other types of cultural exchanges like science, language, art and so on, sport is a vital part of cultural soft power which bring greater unity and national cohesion and expand a nation's space in the international sphere of diplomacy and relations [14].

It might properly be said that sport is "schizophrenic" because of its association with frivolous or leisure activity and its very serious role in terms of domestic and international politics. For sure people with different interest utilize sport for amusement and to pass the time, but it has also been part of important diplomatic positions (for example, the ping pong diplomacy between the US and China, 1980 Summer Olympics boycott; and, in an anticipatory vein, the 2022 Qatar World Cup). From our vantage point, sport ought to be considered as a suitable basis for presenting culture and encouraging positive international relations. Although some people believe that sport should be kept clean and free from political issue, perhaps it is better consider it as a part of political life and a tool for diplomacy [8].

\subsection{International Sport Organizations}

International society has many diverse organizations that operate in different contexts. The global society without international organizations and mutually international organizations without global society never substantialize each other, there needs to be structure to connect and facilitate the work of both elements. International organizations are a significant reason for global solidarity and an effective means for international diplomacy and the pursuit of more perfect solutions among nations as they seek to make effective decisions in and for the world [21].

Sajjadi categorized the sport international organizations into two main categories [20]:

(1) IOC (International Olympic Committee);

(2) IFs (International Sport Federations).

The Olympic movement includes the IOC and the hundreds of NOCs (National Olympic Committees). As well within sports and events associated with the Olympics, there are international federations, and the OCOGs (Organizational Committee of the Games), as well as national associations and clubs that are parts of this huge executive sport organization [16].

Mega events like the Summer Olympic Games, Asian Games and the other kinds of hallmark events play a critical role in placing a city or country on a global map. Increasing the number of tourists and the associated increase in revenue, as well as the increased reputation of host country and host city, are the most important advantages that provoke a 
government to support hosting. As the largest and most popular global event, the Olympic Games play an important role in developing and expanding international communications. The Olympic Games have a critical impact on national pride. Different countries, by investing on this mega event, try to maintain and develop their national pride by presenting themselves on a world stage [13].

Of course, the Olympic Games are not the only tool or opportunity for such building an international profile. The OCA is the most important sport organization in Asia which holds Summer Asian Games every four years. In addition to the biggest continental event, it is in charge of some other events [1]: (1) Asian Winter Games; (2) Asian Indoor Games; (3) Asian Beach Games; (4) Asian Martial-Art Games; (5) AYG (Asian Youth Games).

Likewise, FIFA plays a critical role in international relations. A giant organization with 209 members (more than United Nations Organization), FIFA was founded by seven European footballing nations in 1904. The story of this growth, first at a continental level and then moving into its transcontinental reality, is that association football itself was coterminous with the rise of industrial society and nations and now associated with the transnational reality of media and multinational corporate sponsorships [25].

\section{Conclusion}

The first question that we need to ask ourselves before explaining how to get involved with diplomacy is: What actually constitutes diplomacy? Public diplomacy is, at its core, the sharing of diplomatic messages between political entities that improve the relationship between nations. Public diplomacy was used as a vehicle to promote nation's soft power for winning the Cold War. In this space, sport is an ideal vehicle, capable of fomenting a domestic and perhaps even international collective culture and a safe space for nations to countries symbolize their prowess and challenge each other. By sending delegations of athletes abroad, nations can promulgate international relations through a foundation built upon sporting exchanges and related tourism. Correspondingly, the suspension of a proposed sport visit to another nation can be used by states as means to safely engage in public conflict with specific government and its policy makers.

The significance of the phenomenon of sport is not inherent but manifests itself in the uses to which it is put in society. In fact, sport symbolizes the international environment while also being a pragmatic tool of that environment. Its manifold uses serve a variety interests in international relations, a usefulness that can only increase as the effect of sport becomes more widely recognized and understood. The additional presence and symbiosis with the mass media will simply enhance the centrality and import of sport to diplomacy in the new millennium.

Currently, the ability of a country or international actor to present an appropriate and attractive image, via sport, to the international community can provide great opportunities for political and economic development. On the other hand, ignoring this fact can lead to a country's isolation.

Increased international attention to soft power and public diplomacy can be considered the most important component of creating positive image in international society. Sport organizations as main actors of NGOs can promote or decreased the image of a nation. Even the impact for a city awarded hosting rights for the Summer Olympic Games is considerable, as people admire their ability to be successful actors across different political, social, economy and cultural domains. Further elevation to the IOC or FIFA can serve as a kind of verification sign for a nation's importance or superiority. All in all, the assumption that mega events such as the Summer Olympic Games are good for states and their citizens rests on a number of conjectures that also serve as an event's legacy. The most five prominent legacies are:

(1) Success of elite athletes can inspire most of 
youth to take part in sport to improve their healthiness;

(2) In comparison with the other forms of tourism, Olympic Games are economically lucrative and bringing a huge revenue for hosting nation/city;

(3) Olympic Games engendered a "feel cool" factor among citizens of the host nation;

(4) Urban and rural regeneration accelerated;

(5) Nations benefits by casting themselves internationally that introduce their culture and pursue national interest in international relations.

\section{References}

[1] Pigman, G. A. 2014. "International Sport and Public Dimension; Governments, Sport Federations and the Global Audience.” Diplomacy \& State Craft 25 (1): 94-116.

[2] Deos, A. 2013. "Sport and Relational Public Diplomacy; the Case of Newzealand and Rugby World Cup 2011." Sport in Society 17 (9): 1170-86.

[3] Murray, S. 2012. Sport Diplomacy: A Hybrid of Two Halves. Brisbane: Diplomatic Studies Section of Intrernational Studies Association Press.

[4] Markovits, A. S., and Rensmann, L. 2010. Gaming the World: How Sports Are Reshaping Global Politics and Culture. Princeton, NJ: Princeton University Press.

[5] Grix, J. 2013. Sport Politics and Olympic. Political Studies Review 8 (11) 15-25.

[6] Shariati, M., Goudarzi, M., and Azari, A. 2013. "An Investigation of the Relationship between the Success of Countries at the Shenzhen 2011 Summer Universiade with Educational and Demo-Economic." Social and Behavioral Sciences 22 (11): 803-7.

[7] Doosti, M. 2012. Explanation and Analyses of the Causes and Consequences of Involvement of Politicians to Sport of Iran. Ph.D. thesis, University of Tehran.

[8] Jackson, S. 2013. "The Contested Terrain of Sport Diplomacy in a Globalizing World." International Area Studies Review 4 (6): 274-84.
[9] Preuss, H. 2004. The Economics of Staging the Olympics. London: Palgrave Press.

[10] Feizabadi, M. S., Bakhtiari, M., Rashidzade, H., and Nik, F. 2013. "The Evolution of Television Broadcasting Rights during the Summer Olympic Games." International Research Journal of Applied and Basic Sciences 4 (3): 613-6.

[11] IOC, Fact Sheet. 2014. IOC Media Factsheet. Athen: IOC Press.

[12] Preuss, H. 2002. Economic Dimensions of Olympic Games. Barcelona: International Chair in Olympism.

[13] Bainvel, S. 2005. Sport and Politics: A Study of the Relationship between International Relationship and Football. M.A. thesis, Linkopings University.

[14] Grix, J., and Houlihan, B. 2013. "Sport Mega Events as Part of a Nation's Soft Power Strategy; the Cases of Germany (2006) and UK (2012)." The British Journal of Politics and International Relations 22 (3): 125-39.

[15] Greenwell, C., Bussel, L. A., and Shonk, D. 2014. Managing Sport Events. New York: Human Kinetics Press.

[16] Beacom, A. 2012. International Diplomacy and the Olympic Movement. London: Palgrave Press.

[17] Aalam, A. 2014. Principles of Politics (Persian). Tehran: Ney Press.

[18] Hosseini, A. 2010. The Sport Perception of Presidents. Tehran: Iranian Students' News Agency.

[19] Rezaee, H. 2013. Football and Political Conditions in Iran. Tehran: Official Website of Iran's Football Federation.

[20] Jan, S. A. 2013. The Effect of Supportive Behaviors in Iran Public Diplomacy. Tehran: University of Tehran Press.

[21] Qafoori, M. 2013. International Organizations. Tehran: SAMT Press.

[22] Sajjadi, N. 2014. Sport \& International Relations. Tehran: Hatmi Press.

[23] Nye, J. S. 2004. Soft Power: The Means to Success in World Politics. Public Affairs Press.

[24] Bairner, A. 2001. Sport, Nationalism, and Globalization: European and North American Perspectives. Suny Press.

[25] Millward, P., and Parnell, D. 2014. "FIFA: The Men, the Myths and the Money." Leisure/Loisir 38 (2): 199-202. 